\title{
Curar el cuerpo y salvar el alma. La asistencia en el Hospital General y Pasión (1767-1850)
}

\author{
Florentina Vidal Galache y Benicia Vidal Galache
}

\begin{abstract}
"En el Hospital tiene el hombre estando sano casa donde lo recojan, aunque camine por tierras extrañas, y estando enfermo quien le cure y administre los sacramentos" ?.
\end{abstract}

Para entender el funcionamiento de una institución tan compleja como el Hospital General y Pasión de Madrid hay que considerar una amplia perspectiva histórica de los centros de asistencia a los enfermos, para ver cómo y porqué se crearon, respondiendo a necesidades sociales y principios morales.

En la antigüedad clásica la atención a los enfermos y desgraciados no se hacía bajo los imperativos de la compasión. La asistencia al enfermo "por amor" y el ejercicio de la ciencia de forma gratuita, por un sentimiento de caridad hacia el menesteroso, la incorporación del "consuelo", la actuación que va más allá de las posibilidades de la ciencia, desbordando los conceptos de la ética griega, como el cuidado a los incurables o moribundos y la igualdad de tratamiento a todos los ciudadanos, fueran ricos o pobres, libres o esclavos, van a ser características de la medicina cristiana ${ }^{2}$.

Tras la invasión de los bárbaros, la cultura en Occidente se refugia en los monasterios. El hospital medieval cristiano tuvo su origen en las salas de enfermería de los monasterios, el "infirmariun", en principio dedicadas al cuidado de los monjes, donde no solo estaban los enfermos sino también los ancianos disminuidos. A la sombra de los monasterios surgen

Santos, J., fray, Chronologia Hospitalaria y Resumen Historial de la Sagrada Congregación del Gloriosos Patriarca San Juan de Dios. Madrid, 1716. T. II, pág. 6.

2 Lain Enfralgo, P., Historia de la Medicina. Barcelona. Salvat, 1982, págs. 139-142. 
huertos y jardines dedicados al cultivo de plantas medicinales para abastecer a las boticas de los establecimientos.

El modelo de asistencia nacida en los «infirmariun" (de "in firmus", carente de fortaleza), será después adoptada para el clero secular y los señores pertenecientes a las capas altas de la sociedad.

Otra cosa bien distinta fue el hospital -de "hospes", forastero- nacido también en la Baja Edad Media en los monasterios, pero fuera del recinto de éstos, destinado a dar albergue a los pobres y peregrinos que siguiendo el ideal de la pobreza evangélica, deambulaban por los caminos, viviendo de la caridad de los más afortunados. Aquel "hospitale pauperum» estaba concebido más como un asilo de transeúntes que como un verdadero centro de asistencia a los enfermos. Más tarde el pobre perderá su condición de itinerante y buscará el amparo de las ciudades, donde los obispos, en cuyas manos se ha ido concentrando la riqueza, gastarán buena parte en la creación de hospitales para necesitados. Dada la ineficacia de la medicina, estos centros se convertían en morada permanente de todos los que no podian ganarse el sustento y de los enfermos crónicos que se refugiaban en ellos hasta el fin de sus días.

En Europa, el nacimiento de la burguesia dio paso a la secularización de la hospitalidad, proceso que en España fue mucho más lento de forma que a lo largo del Antiguo Régimen la mayoría de los hospitales continuarán siendo regidos por religiosos.

El concepto cristiano de la caridad como medio de salvación hacía que los poderosos destinaran a la hora de la muerte una parte de su fortuna para la fundación de centros hospitalarios y el pais se llena de pequeños hospitales que iban a vivir de unas rentas, que poco a poco se verán desfasadas de la realidad económica, llegando a tales dificultades que ocasionarán a veces su clausura o la reunión de varios de ellos; en otros casos fue necesario realizar reformas tanto en el plano económico como en el asistencial y organizativo.

Durante la llustración, los intentos de secularizar el ejercicio de la caridad van a dar como resultado que en los hospitales regidos por religiosos se haga notar la creciente participación de las instituciones oficiales, sin que se pierda del todo su carácter primitivo, que les hizo ser no solamente un lugar de curación sino también un albergue indiscriminado de sanos y enfermos, en los que se seguía manteniendo los principios de la orden de San Juan de Dios. 
La evolución en el concepto de la caridad indiscriminada hacia un tipo de beneficencia institucionalizada y los avances de la ciencia, van a dar paso a un hospital cuya acción se concretará en aspectos puramente sanitarios. En España la situación del saber médico a principios del siglo XIX era lamentable: la medicina todavía era leída en latín en la mayoría de nuestras universidades, en terapéutica se seguían los principios de la farmacia galénica y se ha dicho que las purgas y sangrías a que eran sometidos los pacientes costaron tantas bajas como las campañas de Napoleón.

Pero a lo largo del siglo las Ciencias de la Naturaleza y la Medicina van a iniciar unas transformaciones decisivas. El progresivo descubrimiento de los principios terapéuticos activos de los remedios vegetales y la investigación de la acción de los fármacos mediante experimentos en animales, fueron dos hechos determinantes en estos avances. Más tarde vendrían los descubrimientos de Pasteur en el campo de la inmunoterapia y el gran salto adelante de la cirugía, que había tenido su máximo exponente en los Reales Colegios ${ }^{3}$, sería posible gracias a la introducción de la antisepsia (J. Lister 1827-1912) y sobre todo del uso de anestésicos (V.P. Jacson, 1844) que permitieron una paulatina ejecución de operaciones regladas.

A partir de la segunda mitad del siglo XIX la medicina va siendo más eficaz, más técnica y más cara y el hombre, que poco a poco secularizando su mente y valorando su existencia terrena, irá también confiando más y más en las posibilidades diagnósticas y terapéuticas.

Los modelos de asistencia continuarán dentro de unas pautas casi invariables desde siglos atrás: medicina privada, a domicilio, a cargo de los más prestigiosos especialistas para los poderosos; medicina privada también para los que pudiesen costearla. Todo menos el hospital benéfico, hacinado, sucio, y donde se daba una alimentación lamentable, que quedaba reservado para los pobres.

Estos hospitales públicos para la atención de los pobres, que habian estado bajo la tutela real desde mediados del siglo XVIII, pasaron a ser dirigidos y administrados por los ayuntamientos en las etapas liberales. La Ley General de Beneficencia promulgada en 1822, primera legislación completa sobre el tema, preparó el terreno para la reforma de los hospitales, intentada sin éxito durante el reinado de Carlos III - cuando se proyectó una nueva reunión de los hospitales madrileños-. La reforma no

El primero fue el de San Fernando de Madrid (1747), seguido de los de Cádiz (1748). Barcelona (1764), Madrid (1786), etc. 
pudo llevarse a cabo hasta 1836 con el definitivo triunfo de la política liberal por falta de medios económicos, inestabilidad política, falta de tiempo, etc. La crisis del Antiguo Régimen se reflejaba en el mal funcionamiento de casi todas las instituciones benéficas de carácter público, que no recibían a tiempo sus asignaciones y rentas, con el deterioro correspondiente en su atención a los pobres, sobre todo en los últimos años del reinado de Fernando VII. Será ya con el gobierno liberal, a partir de 1836 , cuando se inicie el cambio de orientación en política hospitalaria. En los hospitales públicos, el Rector que dirigía la vida interna del Centro pasa a ser sustituido por un director, un seglar, nombrado por la Junta Municipal de Beneficencia. El médico adquiere un papel preponderante frente a los eclesiásticos y los pobres ya no encontraran en el hospital un lugar de acogida cuando están sanos.

\section{EL HOSPITAL GENERAL Y PASIÓN}

Al establecerse la Corte en Madrid a partir del verano de 1561, la afluencia de gentes llegadas de todos los lugares del reino planteó la necesidad de un hospital para todos los enfermos necesitados que eran atendidos en distintas instituciones de caridad, en su mayoría pequeños establecimientos de fundación particular, con rentas insuficientes y mal gestionados. Unificando sus rentas y limosnas se podría acoger a todos en un sólo centro, como ya se había hecho en otros paises europeos.

Tras un exhaustivo proceso de investigación, Felipe II decidió la reunión de hospitales de Madrid y, antes de cambiar los estatutos fundacionales, pidió la oportuna autorización al Papa. El permiso fue concedido en 1567, pero aún pasaron 14 años hasta que el proyecto pudo ponerse en marcha ${ }^{4}$.

En Madrid había un pequeño Hospital General, situado en la confluencia de la calle del Prado con la Carrera de San Jerónimo, al que fueron agregados el Hospital del Campo del Rey, fundado en 1489 por Garci Alvarez de Toledo, cerca de la actual Puerta de Segovia; el de San Ginés, también de fundación muy antigua, próximo a la parroquia del mismo nombre; el de la Pasión, próximo a la ermita de San Millán, fundado en 1565

4 Constituciones y Ordenanzas para el Gobierno de los Reales Hospitales General y Pasión de Madrid. Madrid, 1780, f. 3. El ejemplar consultado está en la Biblioteca de la Real Academia de Medicina de Madrid. Las noticias sobre el personal y congregaciones asistenciales proceden de este Reglamento. 
por cuatro piadosos caballeros para la curación de mujeres pobres, y el de Convalecientes, fundado y dirigido por Bernardino de Obregón en la calle de Fuencarral y atendido por su congregación. En 1587 quedó realizada la unificación administrativa de los hospitales.

Al Hospital de Antón Martín, donde tradicionalmente se asistía a los infecciosos, se unieron los de San Lázaro y La Paz, dedicados a este tipo de enfermos, quedando así separados los portadores de enfermedades consideradas contagiosas ${ }^{5}$.

Como el viejo edificio de la calle del Prado no tenía la capacidad suficiente, para instalar el nuevo Hospital General se pensó en el del recientemente clausurado Albergue Real para mendigos, fundado por Cristóbal Pérez de Herrera, Protomédico de Felipe II, y situado al final de la calle de Atocha, en una parte de la hacienda cedida por el Cardenal Arzobispo D. Pascual de Quiroga. Al estar alejado del centro de la ciudad, el hospital gozaría de un aire más puro y los enfermos quedarían convenientemente separados del resto de la población; las personas sanas, a la vez que quedaban protegidas de posibles contagios, se librarian del penoso espectáculo de enfermedad y miseria que tanto terror inspiraban. En 1603 se efectuó el traslado aunque el antiguo Albergue Real no estaba totalmente adaptado para sus nuevos fines y en principio las enfermas de la Pasión fueron excluídas por falta de sitio; en 1636 se agregaron al cuerpo principal del edificio unas casas contiguas pertenecientes a D. Juan Luis Gaytan de Ayala, donde por fin quedó alojado el Hospital de la Pasión ${ }^{6}$.

\section{LA ASISTENCIA ESPIRITUAL}

En los estatutos y ordenanzas fundacionales de los hospitales nacidos ya a finales del siglo XVIII quedaba claro que la función de estos establecimientos era tanto el cuidado del cuerpo como la salvación de las almas. En estos centros, en los que la figura del sacerdote era muy importante y donde se hacía una vida en común entre sirvientes y acogidos, se atendía un variopinto conjunto de menesterosos: pobres desvalidos y toda clase de personas marginadas a las que se proporcionaba cumplida asistencia espiritual.

\footnotetext{
5 Actas de la Real Junta de Hospitales, año 1800-1801. Archivo Regional de la Comunidad de Madrid (A.R.C.M.), Fondos Diputación, leg. 4.630.

6 Idem., pág. 34.
} 
A partir de los Reglamentos aprobados por Carlos III en junio de 1760 y corroborados en 1780 podemos conocer la complicada organización del Hospital General y Pasión en la segunda mitad del siglo XVIII, donde se reconocen muchos de los postulados por los que se regian aún la mayoría de los hospitales de caridad desde sus orígenes.

El gobierno del establecimiento estaba a cargo de la Junta de Hospitales que se reunía una vez a la semana; estaba formada por personalidades de la nobleza y eclesiásticos y presidida por el Hermano Mayor. La vida espiritual y material del centro estaba a cargo de 21 sacerdotes que accedían a los distintos cargos por medio de oposiciones, con la excepción del Rector que debía ser elegido entre los 24 consiliarios de la Junta.

La presencia masiva de religiosos en el hospital demuestra que se daba prioridad a la salvación del alma sobre la salud del cuerpo y los Reglamentos así lo confirman: "Considerando la Junta de Gobierno, que el fin ultimado de sus encargos havía de ser la salud de las almas de sus enfermos, tanto mas privilegiada en su cuidado, quanto excede en perfección el alma del cuerpo, trató del establecimiento de un competente numero de Sagrados Ministros» 7.

El Rector, asistido por el Vicerrector, era la máxima autoridad dentro del hospital; dirigia a los demás sacerdotes, encargándoles los auxilios espirituales a los enfermos y los distintos actos religiosos. También debía "...de atender à la puntualidad y vigilancia con que han de hacer sus visitas los Medicos y Cirujanos, asistiendo (quanto mas pudiere) à todas ellas y procurando que se hagan con mucha reflexión, cuidado, y caridad. Cuidará de que en las oficinas de ambas Casas, como son Boticas, Proveedurias, y Cocinas, (que por sí, ò el Vicerrector visitaran diariamente) se administren las especies que contienen, y que siendo de buena calidad, se distribuyan con prudencia, economia y arreglo en la cantidad, qualidad y tiempo à los Recetarios de Medicos, y de Cirujanos, y que se repartan por los respectivos encargados a los enfermos, castigando los descuidos que ocurrieren en estos puntos, con discreción, de modo que prevengan el abuso..." ${ }^{8}$.

El Vicerrector tenia a su cuidado los almacenes y despensas, vigilando el recibo, peso y medida de las especies, alimentos en general y enseres, ocupaciones no le eximían de cumplir con sus obligaciones como religioso.

Idem., pág. 16.

Madoz, P., opus cit. pág. 358. 
Los demás sacerdotes desempeñaban distintos cargos. Los Curas y Tenientes debían confesar a los enfermos recién llegados, administrar los últimos Sacramentos a los más graves, dar la Comunión por las salas los jueves y domingos y oficiar los funerales. Habia un Capellán de Extranjeros que debía conocer varias lenguas. El Colector y Sacristán Mayor eran los responsables de la iglesia, cuidándose de la limpieza, ornamentos, lamparas y joyas; también tenían la obligación de inventariar las existencias de la sacristía y la organización de las funciones solemnes (misas mayores, funerales, etc.). Por último los Capellanes de Agonizantes debian hacer guardias de día y de noche para atender a los moribundos. Otras muchas funciones religiosas, muy claramente distribuidas y especificadas, llenaban la jornada en el Hospital: misas, pláticas en las salas, conferencias de Teología, confesiones y otro sinfín de actos litúrgicos.

El 27 de noviembre de 1791 fue aprobado un nuevo reglamento para la asistencia espiritual de los enfermos. En él se aumentaba el número de sacerdotes a 32, que accedían a los diferentes puestos por oposición. A los aspirantes se les exigía que fueran «hábiles e instruidos, dotados de prudencia, caridad, buenas costumbres y buena reputación». En conjunto, las obligaciones de los sacerdotes eran las mismas que en etapas anteriores, aunque se ponía un especial énfasis en la obligatoriedad de confesar a los enfermos; si éstos se negaban o desinteresaban, se les instruiría en la Doctrina Cristiana; si alguno persistia en su negativa, se recurriría el Rector para que arbitrara otras medidas de persuasión que les llevaran al buen camino ${ }^{9}$.

En 1816 fue actualizado el reglamento con algunas modificaciones. La Guerra de la Independencia había dejado el hospital en muy malas condiciones: las rentas eran mucho menores y habían disminuido de forma significativa tanto eclesiásticos, reducidos a 23 , como el resto del personal. En 1821 había aumentado el número de sacerdotes a $28^{10}$.

En 1848, en plena etapa liberal, la plantilla de religiosos quedó reducida a un Capellán Director, 6 Capellanes Primeros, 6 Capellanes Segundos y 2 Sacristanes ${ }^{11}$. El clero habia perdido su protagonismo en el centro que a partir de 1836 estubo dirigido por un seglar, nombrado por el Ayuntamiento a propuesta de la Junta Municipal de Beneficencia. La evolución hacia un nuevo concepto de hospital estaba ya en marcha.

\footnotetext{
9 Reglamento para la asistencia espiritual de los enfermos y distribución de todos los demás exercicios Eclesiásticos que debe observar el Clero de los Reales Hospitales General y Pasión de Madrid. Madrid, 1791.

10 Reglamento para la asistencia espiritual de los enfermos del Hospital General y Pasión... Madrid, 1816.
} 


\section{LAS CONGREGACIONES PIADOSAS}

Los Hermanos Obregones eran una congregación fundada por el Venerable Bernardino de Obregón, primer Rector del antiguo Hospital General, para la asistencia de los enfermos; después de la reunificación, los obregones siguieron desempeñando su labor de enfermeros en el nuevo hospital.

El Hermano Mayor era el encargado de nombrar a cada uno de los responsables de las enfermerias y tenía la responsabilidad de las ropas y utensilios de las salas: cuando llegaba un nuevo enfermo, le suministraba una muda limpia para la cama y una camisa que sustituyera a los habituales harapos. También hacía una ronda nocturna, vigilando el cumplimiento de los turnos de vela y se encargaba de que los hermanos salieran a pedir por las casa hilas para las curas.

El Enfermero Mayor controlaba a los practicantes seglares y a los hermanos enfermeros. Sus deberes abarcaban un amplio campo de actividades sanitarias, como recorrer las salas para ver si se cumplían las dietas prescritas o asistir a las visitas junto a los médicos y cirujanos, controlando si las sangrías y otros remedios se aplicaban puntualmente. También realizaba labores puramente domésticas como tocar la campana para levantar a los sirvientes, a las cuatro en verano y a las cinco en invierno, inspeccionando la limpieza de las salas y camas de los enfermos, castigando los descuidos y omisiones. El atareado personaje estaba revestido de cierta autoridad policial porque ejercía un control directo sobre las entradas y salidas del personal y no permitía que los practicantes faltaran por las noches a sus puestos; vigilaba estrechamente para que en las salas no se jugara a naipes, dados, tabas, damas y otros entretenimentos por demás mundanos y se cuidaba de que los practicantes no utilizaran armas dentro ni fuera del Hospital ${ }^{12}$.

La actuación de los obregones fue criticada en más de una ocasión; aparte de incumplir con sus obligaciones fueron acusados de robar pertenencias del Hospital. El 16 de agosto de 1801 se decidió en la Junta Directiva:

"Que se prebenga al Hermano Mayor de la Congregación de Obregones el poco cuidado que prestan sus individuos en el aseo y asistencia a los enfermos, se les be continuamente por las calles sin aquella

Madoz, P., opus cit. pág. 358.

12 Constituciones... 1780, págs. 45-50. 
moderacion y compostura que se requiere y que procure por su parte detener las funestas consequencias que de semejantes abusos resultan»

Poco días más tarde, en la Junta del 23 de agosto, se pedia al Hermano Mayor se responsabilizara de la falta de 253 mantas. La Junta el 20 de septiembre pedía al Rector y a la Contaduria que establecieran un plan para cortar de raíz la desaparición de las ropas y otros abusos ocurridos en el establecimiento ${ }^{13}$.

Pese a estas reticencias, los obregones permanecieron en el Hospital incluso durante el trienio liberal. El 18 de octubre de 1821 las congregaciones hospitalarias fueron disueltas por Real Orden pero como no había personal cualificado se contrató a los obregones en atención a la labor humanitaria que hasta entonces habian desarrollado. Un caso similar fue el de los Hermanos de San Juan de Dios, orden hospitalaria que atendía a los infecciosos del hospital de su nombre; la congregación fue disuelta y sus individuos expulsados, pero al no encontrar personal que les sustituyera, se le admitió de nuevo bajo contrato.

El reglamento aprobado por la Junta Municipal de Beneficencia en 1846 confirmaba en su empleo a los hermanos obregones para atender a los enfermos, llevar la responsabilidad de las recetas médicas, controlar las ropas del Hospital, realizar cuestaciones a favor de los pobres enfermos, etc. ${ }^{14}$. En 1848 había 31 obregones trabajando en el Hospital General.

Otras muchas personas constituidas en cofradias ejercian funciones asistenciales hospitalarias totalmente gratuitas: al Hospital General acudían los Hermanos de San Felipe de Neri y la Congregación de Animas y al Hospital de la Pasión para mujeres las Hermanas de Nuestra Señora de la Caridad y la Congregación de Animas.

Los Hermanos de San Felipe de Neri eran un grupo hombres seglares que en 1697 levantaron a sus expensas un oratorio y una sala de reuniones en el hospital; en 1701 queda ratificada su concesión por un Decreto de 15 de julio. Todos los días de fiesta se reunían para rezar y más tarde, vestidos con un sayal de saco grosero, atendian a los enfermos. Su reglamento decia: «... a este fin se dividen por Salas; y sobre tratarlos con blandura y cariño, y confortarlos con santos documentos, les hacen las camas y mudan la ropa, los limpian, los lavan, y les sirven la cena, practicando estas

13 Madoz, P., opus cit. pág. 358.

14 El Reglamento del Hospital General y Pasión de 1846 se puede consultar en Actas de la Junta Municipal de Beneficencia, 1856, A.R.C.M., Fondos Diputación, libro 432, f. 7. 
acciones de rodillas. ¡Que mayor confusión de la soberbia! ¡Y que mas eficaz exemplo para mejorar la vida!". Sin duda la postura en actitud tan humilde sería una buena cura para la soberbia y un ejemplo magnífico para cuantos contemplaran sus penosos desplazamientos por las destartaladas salas del hospital, excelente escenario para toda clase de actuaciones aleccionadoras, pero parece dudosa la eficacia de su labor y desde luego serian un obstáculo y un incordio para los demás empleados.

En 1707 un grupo de 26 mujeres de la nobleza y familias adineradas formaron una congregación, dirigida por el sacerdote D. Juan Antonio de Barrios, que tomó el nombre de Hermanas de la Caridad. Los días de fiesta acudian al Hospital de la Pasión, donde tenian su capilla y sala de oración, con un uniforme de estameña para ocuparse de las enfermas más disminuidas y ayudarlas en su aseo. Les llevaban dulces suaves, chocolate y consuelo.

La Congregaciónes de las Animas, integrada por nobles y personajes de la Casa Real, junto con la del Santisimo Cristo de la Agonía en el Hospital General y la de Nuestra Señora de las Angustias y Animas del Purgatorio del Hospital de la Pasión se ocupaban de la macabra tarea de enterrar a los pobres y aplicar por ellos innumerables sufragios.

Cada congregación tenía 12 capellanes que celebraban misas diarias por el alma de los fallecidos en las mismas salas de los enfermos, para que todos pudieran participar; la Congregación de las Animas costeó hasta 5.000 misas de alma en un año. También sufragaban otros actos religiosos solemnes en los días de fiestas: sermones, pláticas, etc ${ }^{15}$. Además de los bienes espirituales, la incansable actividad de todas estas personas piadosas y la participación en tantos actos religiosos debía ser una buena terapia para los pobres que con el ajetreo se olvidarian de su triste situación.

No conocemos cuando dejaron de actuar estas caritativas asociaciones; en los documentos consultados del siglo xIx no consta ninguna noticia sobre su continuidad.

\section{LA ASISTENCIA MÉDICA}

En 1780 había nueve médicos para asistir a los más de 1.000 enfermos de los dos hospitales; seis de los facultativos ejercian en el Hospital

\footnotetext{
Las noticias sobre cofradias han sido consultadas en Constituciones..., 1780, págs. 19-21.
} 
General y tres en la Pasión. Para ser admitidos debian ser aprobados por el Tribunal Real del Protomedicato, tras realizar una dura oposición.

Al frente de los médicos estaba el más antiguo, el Médico Mayor, que debia llevar un control directo sobre las salas, a las que hacia dos visitas diarias, y asistir a los enfermos de medicina que se encontraran en las salas de cirugía (los cirujanos no podían administrar remedios «internos»). Una vez al mes reunia a todos los demás médicos en sesión clínica, donde se analizaban las enfermedades padecidas en el hospital y los métodos curativos empleados, para informar más tarde a la Junta Rectora.

Los médicos y los cirujanos hacian la visita junto con un obregón, el Boticario, que anotaba los medicamentos recetados, y el Remedios Mayores - nombre dado al practicante de medicina más importante-que también debía tomar nota de los alimentos, medicinas, sangrías y todas las particularidades de cada caso; de esas anotaciones se deducian las obligaciones de los practicantes. Al finalizar la visita los médicos examinaban y firmaban las libretas ${ }^{16}$.

Había cinco cirujanos para los dos Hospitales. La provisión de sus plazas, así como las de los practicantes, se realizaba también por oposición. Según el reglamento, se daba el título de Cirujano Mayor al de más antigüedad y méritos. Entre sus obligaciones estaba la de realizar las grandes operaciones y curar por su mano a todos los enfermos que las hubieran sufrido. Antes de realizar ninguna intervención de riesgo «...como sacar la piedra de la Vegiga, Amputacion, Bubunocele, Trépano, Empiemas, etc...» debía reunir al resto de los cirujanos e informar a un médico, por si había alguna complicación. El postoperatorio era seguido por los practicantes, turnándose a la cabecera del paciente.

El Cirujano Mayor convocaba una vez al mes al resto de los cirujanos y a los practicantes, para llevar una estadística de los enfermos fallecidos y curados. Los demás de los cirujanos se distribuían por salas, realizando dos visitas al día.

Los practicantes de cirugia estaban dirigidos por un Practicante Mayor, encargado de suplir las ausencias y enfermedades de los cirujanos. Se concedia este puesto a la persona capaz por sus estudios de llegar a ser cirujano al quedar vacante alguna de las plazas por fallecimiento, dimisión o ascenso del cirujano de menor antigüedad. Tenía que asistir a las curas con el Cirujano Mayor, dándole cuenta de las entradas y bajas. Los

16 Cf.: Constituciones... 1780, págs. 51-54. 
practicantes debian ser solteros y residir en el hospital, para estar disponibles en cualquier momento.

En la plantilla había cinco plazas de sangradores que se cubrian con los practicantes más sobresalientes, "para darles estimulo"; previamente debían pasar un examen ante el Cirujano Mayor que tenía en cuenta la antigüedad, buenas costumbres "y el método que hayan observado en la asistencia y alivio de los pobres enfermos" ${ }^{17}$.

Los practicantes asistían a los médicos, ayudaban en las curas y "cumplian con el remedio que estuviese a su cargo", de forma que se encargaba de lo más fácil el practicante recién llegado y así sucesivamente hasta llegar al Remedios Mayores, que era el puesto de mayor responsabilidad. Los nombres de cada especialidad son por demás aclaratorios: «caldista», "agüista», etc. El "unturista» realizaba labores un tanto dispares: además de administrar las unturas ponía ventosas, lavativas, ( «reparos por dentro y por fuera»), cortaba el pelo y la barba y aplicaba sanguijuelas. También subia de la botica los medicamentos y aguas y acompañaba a los mozos que traían la comida, hacian las camas, transportaban colchones y conducían los cadáveres a la capilla. El polifacético "unturista" no dormía a placer porque, además de las correspondientes guardias de día, velaba algunas noches. Como premio, a los más destacados "unturistas» se les enviaba a las salas de cirugía, donde debían llevar una vida más sosegada ${ }^{18}$.

El 31 de marzo de 1808, y sin duda dictada por la angustiosa situación de preguerra, se promulgó una Real Orden por la cual cesaba la enseñanza de la Cirugía en el hospital y se mandaba que los practicantes que asistieran a las lecciones del Real Colegio de Cirugía, con la consideración de discípulos matriculados en él. La gran afluencia de enfermos en los meses siguientes obligó a los practicantes a abandonar las aulas del Real Colegio y dedicarse exclusivamente a la atención y cuidado de los enfermos ${ }^{19}$.

Pasada la Guerra de la Independencia el personal sanitario se amplió de forma significativa. En 1821 había ya 17 médicos -12 de número o de plantilla y 5 de entrada-, y 15 cirujanos. Los practicantes eran 109; en total, el personal contratado ascendía a 403 personas ${ }^{20}$.

17 Idem, págs. 58-63.

18 Idem, págs. 54-57 y 63-66.

19 Aparicio Simon, J., Historia del Real Colegio de San Carlos de Madrid. Madrid. Aguilar, 1956, pág. 91.

20 ORIve, J., Estadistica de los Establecimientos de Beneficiencia de Madrid. Madrid. 27 de junio de 1821. Archivo de Villa, Sección Secretaría, (A-V.S.) 2-334-47. 
En mayo de 1833 fue aprobada por la Junta la admisión de las Hermanas de la Caridad para atender a los enfermos del Hospital General y Pasión. El 24 de noviembre del mismo año, fueron expulsados todos los practicantes del General, por protestar con violencia, "cometer desórdenes", por la presencia de las monjas en el hospital de hombres ${ }^{21}$; $\sin$ duda tenían miedo de que las competentes religiosas, que ya trabajaban con gran éxito en otros centros asistenciales benéficos, les arrebataran sus puestos de trabajo. En el reglamento del Hospital General de 1846 quedaban confirmadas las Hermanas de la Caridad en los puestos que hasta entonces habían desempeñado. Los conflictos de competencia se resolvieron con el tiempo y en 1848 había en el Hospital 31 religiosas y 101 practicantes de cirugía y medicina trabajando en aparente armonía. En la misma etapa había 14 médicos con categoria $1^{\circ}$ y $2^{\circ}$, ocho de plantilla, y cuatro de entrada, un Cirujano Mayor y un Cirujano Segundo, siete cirujanos de plantilla y cuatro de entrada. Se accedía a las plazas por una reñida oposición ${ }^{22}$.

En conclusión, hasta bien entrado el siglo XIX la asistencia espiritual a los enfermos fue una preocupación constante en el Hospital General y Pasión de Madrid. Si comparamos el número de personas, religiosos y seglares, dedicados a labores piadosas con el de facultativos, queda claro el espíritu que imperaba en el centro, tanto o más preocupado por la salud de las almas que por la curación de los cuerpos. La labor de las cofradías asistenciales, integradas fundamentalmente por nobles y poderosos, deja también patente que aún estaba muy arraigado en la sociedad el sentimiento de la caridad y la obligación de prestar ayuda a los menos favorecidos.

\footnotetext{
20 Orive, J., Estadistica de los Establecimientos de Beneficencia de Madrid. Madrid. 27 de iunio de 1821. A.V.S., 2-334-47.

21 Libro de Actas de la Junta de Hospitales. Año 1833. A.R.C.M., F.D., libro 452, sesiones de 20 de mayo y 26 de noviembre.

${ }^{27}$ Madoz, P., opus cit. págs. 360.
} 